\title{
CRYSTALLINE-AMORPHOUS INTERFACES
}

AND THEIR RELATION TO GRAIN BOUNDARY FILMS

DOE/ER/ $45381--3$

DE9 2009812

\author{
A Report \\ for the 3-Year Period
}

15 November 1988 through 14 November 1991

C. Barry Carter

DEPARTMENT OF CHEMICAL ENGINEERING AND MATERIALS SCIENCE,

AMMUNDSON HALL, UNIVERSITY OF MINNESOTA,

MINNEAPOLIS, MN 55455

Work performed at :

DEPARETMENT OF MATERIALS SCIENCE \& ENGINEERING,

BARD HALL, CORNELL UNIVERSITY,

ITHACA, NY 14853

February 3, 1992

subrnitted to

US Department of Energy
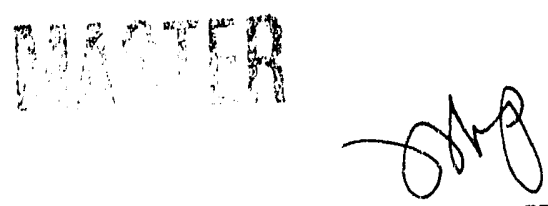

DISTRIBUTION OF THIS DOCUNIENT IS UNVLINAITEM 


\section{CONTENTS}

Contents

\$1. Introduction 1

\$2 Questions Being Addressed 1

$\$ 3$ Summary of Work Done 2

$\$ 4$ Future Problems 3

\$5 The Use of TEM 4

$\S 6$ The Choice of Materials 4

$\$ 7$ Development of This Program 5

§8 References $\quad 5$

§9 Results from 'This DoE Program (1988->1991) 6

Publications 6

Invited Talks Concerning this Program, 1988- $\quad 8$

Other Conference Activities Related to this Program, 1988- 8

Unpublished Contributed Talks from our DoE Programs, Nov. 1988- 9

$\$ 10$ Personnel Involved in this DoE Programs 9

\section{DISCLAIMER}

This report was prepared as an account of work sponsored by an agency of the United States Government. Neither the United States Government nor any agency thereof, nor any of their employees, makes any warranty, express or implied, or assumes any legal liability or responsibility for the accuracy, completeness, or usefulness of any information, apparatus, product, or process disclosed, or represents that its use would not infringe privately owned rights. Reference herein to any specific commercial product, process, or service by trade name, trademark, manufacturer, or otherwise does not necessarily constitute or imply its endorsement, recommendation, or favoring by the United States Government or any agency thereof. The views and opinions of authors expressed herein do not necessarily state or reflect those of the United States Government or any agency thercof. 


\section{§1. INTRODUCTION}

The presence of glass in grain boundaries greatly enhances sintering, in part, because transport of matter along and across the intergranular regions is faster. The glass does not simply act as a catalyst but also changes the character of the interfacial regions. In particular, it tends to encourage faceting of the grains; the scale of this faceting may vary from nanometers to microns. After processing, the glass may remain as a thin layer in the interface during preparation of the polycrystalline compact as was initially demonstrated for $\mathrm{Si}_{3} \mathrm{~N}_{4}[1]$ and proposed for other ceramics (see, e.g., [2]). The glass may also crystallize to form an intergranular crystalline layer or it may withdraw frorn the planar interfaces into three-grain and four-grain junctions (the dewetting process).

In other situations, great care may be taken to ensure that no glass is present during processing but the glass may subsequently enter the interfacial region during processing or service of the component.

In either case, the properties of the ceramic may be greatly influenced by the presence of any glass in the grain boundary; a dramatic example is the effect on mechanical properties (e.g., for $\mathrm{Si}_{3} \mathrm{~N}_{4}$ or $\mathrm{Al}_{2} \mathrm{O}_{3}$ ), which also aids sintering, although other properties (e.g., the thermal conductivity for AIN) may be just as strongly affected.

The present program has begun to examine how glass affects and interacts with crystalline ceramics. The main aim of the program is to examine how glass moves into and out of grain boundaries and why this movement takes. By understanding this process we will be better able to control this important aspect of many ceramic materials. Since TEM is the main tool used in this investigation, we will continue to develop methods for analyzing interfaces as part of this program.

Many properties of ceramic materials are directly influenced by the presence of glass. For the materials investigated in this study the important parameters are the final mechanical strength and ease of processing.

a) The strength of ceramics at high temperatures may be drastically lowered if a glass is present, or forms, at the higher temperature. The reason is simply that the glass becomes viscous at a relatively low temperature; it then cannot support a shear stress and allows rapid deformation of the material. In other circumstances, the presence of the glass may be beneficial since it may assist the branching of cracks by generally weakening grain boundaries.

b) Processing of ceramic materials is much easier in the presence of a liquid phase, in part for the same reason - the glass allows deformation at lower temperatures; diffusion is also faster through a glass. Thus the glass allows the sample to be shaped and/or densified at lower temperatures (e.g., [3]).

\section{\$2 QUESTIONS BEING ADDRESSED}

The program has begun to address four specific question concerning these glassy films:

How does the grain boundary wetting process proceed?

How does the grain boundary dewetting process proceed?

Page -1- 
What factors control the way a glass wets an interface?

How can a thin glassy film in an interface be characterized experimentally?

a) How does the grain boundary wetting process proceed?

If glass is not already present at a grain boundary, then, how does it penetrate into the grain boundary? What factors determine how quickly penetration will take place? A related question concerns the actual mechanism for the lateral movement of crystalline-amorphous interfaces.

b) How does the grain boundary dewetting process proceed?

If glass is already present at a grain boundary, then, how does it recede from the grain boundary and can it leave a completely clean grain boundary? (The process described in ' $a$ ' may not be reversible.)

c) What factors control the way a glass wets an interface?

Experimentally, it appears that some grain boundaries are wet by an amorphous phase while others are not. It is important to determine the conditions under which the glass is entering, or leaving, an interface. We need to know the composition of the glass and whether or not this phase is in equilibrium with the crystalline material-both thermodynamics and kinetics are important here.

d) How can a thin glassy film in an interface be characterized experimentally?

Techniques have been developed for characterizing such amorphous films but their interpretation is not always unambiguous. The techniques used to images such thin films in the TEM include high-resolution imaging, Fresnel-fringe (defocus) imaging and diffusedark-field imaging. One difficulty which is encountered in all TEM studies results from the need to study a thin electron-transparent film. The sample-preparation process preferentially removes the lower-atomic-number material or thins faster where the atomic bonding is weaker. Clearly grain boundaries are likely sites for preferential thinning. The reliability of techniques used for identifying glassy films in grain boundaries must be assessed.

\section{\$3 SUMMARY OF WORK DONE}

\section{a) How does the grain boundary wetting process proceed?}

Our work has demonstrated the role of ledges when the glassy is relatively thick. We have observed the movement of a group of individual ledges; the interpretation is that the glass was growing into the crystalline material by the movement of these ledges. A particularly important feature of this experiment is that the interface can be studied after repeated heattreatments--the same steps can be studied by repeated annealing of the TEM sample either with or without the glass-forming vapor. It is, of course, important to know that the sieps were present at the reaction temperature. There are many similarities between the penetration of a very thin glassy film into a grain boundary and the propagation of a crack--in the former case the driving force is chemical, while in the latter it is mechanical. It is also likely that the "film tip" is not as sharp as the mechanical crack tip. In our study we are considering the effect of grain boundary structure (i.e., dislocations and steps) on the movement of a glassy films into the interface.

b) How does the grain boundary dewetting process proceed? 
We have developed a method for studying this phenomenon; a grain boundary is prepared which is initially coated with a thin film of glass. The same bicrystal can then be processed in different ways and the resulting interface studied. The technique was first used for $\mathrm{Si}$ where the glass layer is the naturally occurring oxide. In both our Si and alumina studies, the glass dewetted the interface and formed into pockets in the interface and shows that dislocations form in the low-angle grain boundary as the glass recedes-there are no dislocations present when the grains are not in intimate contact. The large pores clearly formed after the bicrystal had been prepared since the pores grew equally into both grains. The presence of the glassy phase in these regions can be confirmed using EDS. The same process was studied at much lower magnification in the alumina grain boundary. In this case, the interface was studied using transmitted visible light since the alumina grains are transparent. As the annealing is continued, the glassy regions become more anisotropic in shape as would be expected from the thin-films studies.

c) What factors control the way a glass wets an interface?

In our study, we will consider glasses which are in chemical equilibrium with the crystalline material and others which are not.

d) How can a thin glassy film in an interface be characterized experimentally?

We have developed methods for cleaning TEM foils; these methods will be used in this study in modified form since it is important that the glass not be removed from the thin foil or altered in any way by the cleaning process. When the films are thin, we have demonstrated conclusively it is essential to use a combination of techniques.

\section{\$4 FUTURE PROBLEMS}

The questions posed in $\$ 2$ must continue to be investigated and to this end two experimental approaches are being used:

a) Create known grain boundaries and add glass

b) Create a glassy film between two grains and process the composite.

a) Create known grain boundaries and add glass.

This approach provides information on the penetration of grain boundaries by glass and give a method of studying the movement of individual steps. Grain boundaries are being prepared both by hot-pressing together monocrystalline slices and by growth from the melt using the new Cornell ceramic-crystal growth facility. The glass will be introduced via the vapor, liquid or solid phase in three distinct experiments.

The experiment using the vapor-phase reaction provides a unique capability of looking at the reaction at different stages and then continuing the reaction. The geometry of the growth of such pockets emphasizes the strong crystallographic anisotropy of the aiumina: the long facet is invariably parallel to the (0001) plane. What appear to be holes in the sample are actually pockets of glass. This type of sample is clearly ideal for a TEM study. There is actually an excess of glass present on the TEM sample which may help prevent preferential thinning of the glass during the reaction-temperatures of $\sim 1400^{\circ} \mathrm{C}$ were used in this experiment. Although this experiment is referred to as a vapor-phase reaction, glass is deposited on the TEM sample from the vapor and then reacts with the sample; it is therefore, at least in part, a solid-state, thin-film reaction. 
Reactions with the liquid involve encapsulating a section from a bicrystal in a glass-forming powder. This is the approach taken by Clark [4], Flaitz [5] and Shaw [6]. The use of controlled bicrystals will allow the same interface to be studied under different conditions. The reaction with the solid will be carried out using a thin-film geometry with the grain boundary in the cross-section orientation similar to the classic geometry for diffusion experiments. In this case the glass will be deposited using pulsed-laser ablation. This deposition technique will also allow the wetting of the surface by a range of glasses to be investigated-the crystallography of the surface and the chemistry of the glass can both be derermined directly in the TEM.

b) Create a glassy film between two grains and process the composite.

The preparation of an interface using this process has been described above. In the examples studied, the glass was found to withdraw into pockets within the interface and to leave a structured grain boundary behind. Once prepared, the heat-treatment can be repeated to allow changes to be observed in the interface. In order to create interfaces where the thin film will be stable, the orientation of the adjoining surfaces and the chemistry of the thin film will be varied. Another important variable is the thickness of the glass layer-the thickness is often reported to be $\sim 10 \AA$ which is close to the resolution limit of many of the techniques used to examine it. Furthermore, if the glass is partially ordered at the interface as has been suggested, then the actual thickness of "glass" will be difficult to determine; we will therefore concentrate our efforts on studying films which are thicker than $\sim 50 \AA$.

\section{§5 THE USE OF TEM}

The primary experimental techniques used for this study will involve the transmission electron microscope. The reasons for utilizing these techniques can be appreciated by noting that the amorphous layer which may be present at the interface may only be $10 \AA$ wide. Furthermore, the interface may facet over short $(<1000 \AA)$ distances and contain steps which are only nanometers high. It is also essential that both grains are observed, so that techniques requiring the sample to be broken along the interface would be inappropriate. Since the interpretation of images in the TEM is often not straightforward, as part of this program, we will continue to develop approaches to simulate the contrast at interfaces which may be viewed either edge-on or inclined to the electron beam.

\section{§6 The Choice of Materials}

Experimental studies focussed on several different materials, $\mathrm{Al}_{2} \mathrm{O}_{3}, \mathrm{MgO}, \mathrm{MgAl}_{2} \mathrm{O}_{4}$ and $\mathrm{Si}$ (and Ge). The group as a whole allows the effects of both structure ("hexagonal", cubic) and bonding (ionic, covalent) to be varied, while each particular material has itself been chosen for detailed study for several reasons. Each material also serves as a model for related materials. In particular the following points are emphasized:

i) All of the materials are available as high-purity single crystals which can be used to manufacture well-characterized bicrystals.

ii) In many oxides, the oxygen sublattice approximates to either a hexagonal closc-packed ("hcp") or face-centered cubic ("fcc") structure. 


\begin{abstract}
$\mathrm{Al}_{2} \mathrm{O}_{3}$ is a technologically important material and is one of the most extensively investigated. My research group has been working with this material since 1979 . We have made bicrystals by hot-pressing single crystals at $1900^{\circ} \mathrm{C}$ and have been heat-treating thin foils and bulk samples for over four years.

MgO is, as a model material, the cubic counterpart of alumina. The crystal structure is particularly simple. Bicrystals can be prepared by the same hot-pressing techniques as are being used for $\mathrm{Al}_{2} \mathrm{O}_{3}$, we have already worked on grain boundaries in this material as part of a study of creep in ceramic materials [7]. We are also familiar with heat-treating thin samples of $\mathrm{MgO}$. The spinel is also cubic but allows processing at lower temperatures and gives some flexibility in stoichiometry.

The work on $\mathbf{S i}$ (and $\mathrm{Ge}$ ) provides a helpful comparison with $\mathrm{MgO}$ (both are face-centered cubic). Grain boundaries can be fabricated in the same manner using lower temperatures. As illustrated above, we have demonstrated that this system can be used to examine the geometry of amorphous phases at the interface. In addition, in this case, a relatively pure glassy material can be formed in a controlled manner by the controlled introduction of oxygen to the system. This research will be directly relevant to the characterization of grain boundaries in $\mathrm{SiC}$ and $\mathrm{Si}_{3} \mathrm{~N}_{4}$.

The amorphous material can be introduced in several ways, depending on the sample geometry. The approaches which have been used include reaction with the vapor and direct deposition of the thin film on the surface. We have demonstrated that, in principle, pulsedlaser ablation allows deposition of thin glassy films of almost any composition.
\end{abstract}

\title{
\$7 DeVelopment of This Program
}

This program began at Cornell University in November 1988; this study was initiated in a previous program which terminated at that time. In the first year, David Theodore (now with Motorola) and Jeff Maggard extended the exploratory study for producing bicrystals containing a thin glassy phase; this work was begun by David Susnitzky (now with Dow Chemical). René Rasmussen developed an approach for modelling the Fresnel fringe contrast from edge-on interfaces and developed a program for the simulation of many-beam diffraction contrast images. He also worked with Stuart McKernan, who has been partially supported by this program, to implement simulation and processing packages for interpretation of high-resolution TEM images of grain boundaries.

\section{\$8 REFERENCES}

1. Krivanek, O. L., T. M. Shaw and G. Thomas. J. Appl. Phys. 50(6): 42223, (1979).

2. Brook, R. J. Adv. Ceram. 3: 272 (1981).

3. Kwon, O.-H. and G. L. Messing. The Morphological Stability of Continuous Intergranular Phases. Mat. Sci. Res. 20: 41 (1986).

4. Clark, D. R. Mat. Sci. Res. 13: 303 (1980).

5. Flaitz, P. F. Ph.D. Thesis, UC Berkeley, (1981).

6. Shaw, T. M. and Duncombe, P.R., J. Am. Cerarn. Soc. 74(10): 2495-2505 (1991).

7 Dodsworth, J., C. B. Carter and D. L. Kohlstedt. Adv. Ceram. 6: 73 (1983). 


\section{§9 RESULTS FROM THIS DOE PROGRAM (1988->1991)}

\section{Publications}

A: Book Chapter; C: Conference Proceedings; G: Group Paper; J: Journal; T: Thesis;

A1. Norton, M.G. and Carter, C.B., 1990, in "Atomic-Level Properties of Interface Materials," Eds D. Wolf and S. Yip (Chapman and Hall, London), "Grain and Interphase Boundaries in Ceramics and Ceramic Composites." (due out in Spring 1992)

J68. Skrotzki, W., Wendt, H., Carter, C.B. and Kohlstedt, D.L., 1988, Phil. Mag. A57 (3), 383-409, 1988. "Secondary Dislocations in [011] Tilt Boundaries in Germanium."

J70. W. Skrotzki, H. Wendt, C.B. Carter and D.L. Kohlstedt, 1988, Acta Met. 36 (4), 983994, "The Relation between Structure and Mechanical Properties of a $\Sigma=51$ Tilt Boundaries in Germanium."

J72. C.B. Carter, 1988, Acta Met. 36(10), 2753-2760, " $\Sigma=99$ and $\Sigma=41$ Grain Boundaries."

J85. Veyssière, P. and Carter, C.B., 1988, Phil. Mag. Lett. 57 (4), 211-220. "Dissociation of Dislocations in $\mathrm{MgAl}_{2} \mathrm{O}_{4}$ Spinel Deformed at Low Temperatures."

J94. Rasmussen, D.R., Simpson, Y.K., Kilaas, R. and Carter, C.B., 1988, Ultramicroscopy 30, 52-57, "Contrast Effects at Grooved Interfaces."

J97. D. René Rasmussen, Nam-Hee Cho, David W. Susnitzky and C. Barry Carter, 1988, Ultramicroscopy 30, 27-32, "Determination of the Lattice Translation across Antiphase Boundaries."

J104. Susnitzky, D.W. and Carter, C. B., 1991, Submitted to J. Am. Ceram. Soc. "Surface Structure of Heat-treated Ceramic Thin Films." (Being revised)

J105. Smith, D. A., Elgat, Z., Krakow, W., Levi, A.A. and Carter, C.B., 1989, Ultramicroscopy 30, 8-12, "Multiple Structures in a $\Sigma=27$ Related Boundary in Germanium."

J109. Sung, G. Y., Carter, C. B., Cho, D. H. and Chong, H. K., 1989, J. Materials Science in press, "Sinter-forged $\mathrm{YBa}_{2} \mathrm{Cu}_{3} \mathrm{O}_{7-\mathrm{x}}$ Superconducting Ceramics From The Sprayroasted Powders."

J110. Simpson, Y. Kouh and Carter, C.B., 1990, J. Am. Ceram. Soc. 73(8), 2391-98, "Faceting Behavior of Alumina in the Presence of A Glass."

J111. Sung, G. Y., McKernan, S. and Carter, C. B., 1992, J. Materials Res. 7(2), , "Flat interfaces in Zinc Oxide-Based Varistor Ceramics."

J114. Susnitzky, D.W. and Carter, C.B., 1990, J. Am. Ceram. Soc. 73(8), 2485-93, "Structure of Alumina Grain Boundaries Prepared with and without a thin amorphous intergranular film."

J115. Rasmussen, D.R. and Carter, C.B., 1990, Phil. Mag. 63(3), 503-517, "Interpretation of HRTEM Images of Interfaces Containing Misfit Dislocations Lying Parallel to the Surface of the Sample."

J116. Rasmussen, D.R. and Carter, C.B., 1990 Ultramicroscopy 32, 337-348, "On The Fresnel Fringe Technique for the Analysis of Interfacial Films."

J117. Rasmussen, D.R. and Carter, C.B., 1990, J. Electron microscopy Techniques 18(4), 429-439 "A Computer-program for Many-beam Image Simulation of AmplitudeContrast Images."

J119. D. René Rasmussen, Stuart McKernan and C. Barry Carter, 1990, Phil. Mag. 63(6), 1299-1314 "A Quantitative analysis of Strong-beam a-fringes From \{110\} Antiphase Boundaries in GaAs."

J122. M. G. Norton, S. R. Summerfelt and C. B. Carter, 1990, Appl. Phys. Lett. 56(22), 2246-48, "Surface Preparation for the Heteroepitactic Growth of Ceramic Thin Films."

J123. Rasmussen, D. R., McKernan, S. and Carter, C.B., 1990, Phys. Rev. Lett. 66(20), 2629-2632 "Rigid-Body Translation and Bonding Across \{110\} Antiphase Boundaries in GaAs." 
J133. Susnitzky, D.W. and Carter, C.B., 1991, J. Mater. Res. 6(11), 2403-2411, “Defect/Surface Interactions in Heat-Treated Ceramic Thin Films."

J139. Norton, M.G. and Carter, C.B., 1990, in "Interfaces II" MRS Bulletin 15(10), 51-59, Eds D. Wolf and S. Yip "Interfaces in Structural Cerarnics."

C92. Tietz, L.A., Carter, C.B, Lathrop, D.K., Russek, S.E. and Buhrman, R.A., 1988, Mat. Res. Soc. Symp. Proc., 99, 715-718, "Grain Boundaries in $\mathrm{YBa}_{2} \mathrm{Cu}_{3} \mathrm{O}_{7-\mathrm{x}}$ Thin Films."

C99. Carter, C.B., McKernan, S., Simpson, Y.K., Susnitzky, D.W., and Tietz, L.A., 1988, EUREM 88, Inst. Phys. Conf. Ser. 93(2), 545-546, "Recent Studies of Grain Boundaries in Ceramic Oxides"

C104 Simpson, Y.K. and Carter, C.B., 1988, Proc. 46th Annual Meeting EMSA, 570-571, "The Interaction between Basal-Twin Boundaries and a Glassy Phase in $\alpha$-Alurnina Compacts"

C105 Tietz, L.A., Carter, C.B., Lathrop, D.K., Russek, S.E., and Buhrman, R.A., 1988, Proc. 46th Annual Meeting EMSA, 870-871, "Special Grain Boundaries in $\mathrm{YBa}_{2} \mathrm{Cu}_{3} \mathrm{O}_{7-\mathrm{x}}$ "

C106 Rasmussen, D.R., Simpson, Y.K., Kilaas, R., and Carter, C.B., 1988, Proc. 46th Annual Meeting EMSA, 610-611, "Contrast Effects at Grooved Interfaces"

C111 Smith, D.A., Elgat, Z., Krakow, W., Levi, A.A., and Carter, C.B., 1988, Proc. 46th Annual Meeting EMSA, 592-593, "Structural Multiplicity in a Tilt Boundary in Germanium."

C121. Carter, C.B., McKernan, S., Rasmussen, D.R., Simpson, Y.K., Summerfelt, S.R., Susnitzky, D.W. and Tietz, L.A., 1988, Proc. Mat. Res. Symp. Proc. 139, 189-198, "High-Resolution Microscopy of Ceramics." (Invited)

C122. Carter, C.B., 1988, Surfaces and Interfaces of Ceramic Materials, NATO AS 1, Series E: Applied Sciences, 173, 29-55 "Structure and Microstructure of Interfaces in Ceramic Materials."

C123. Sung, G.Y., McKernan, S. and Carter, C.B., 1989, Proc. 47th Annual Meeting EMSA, San Antonio, Tx, 598-599, "Grain Boundaries in Zinc Oxide-based Varistor Ceramics."

C126. Carter, C.B. and Tietz, L.A., 1989, Proc. 47th Annual Meeting EMSA, San Antonio, Tx, 178-179, "Interfaces in High-T'c Superconducting Oxides."

C151 C. B. Carter, 1990, Proc XIIth Int. Cong. for EM, Seattle, Pp308-309, "Recent Applications of TEM to the Study of Interfaces."

C155 S. McKernan, D. R. Rasmussen and C. B. Carter, 1990, Proc XIlth Int. Cong. for EM, Seattle 4, Pp362-363, "The Determination of the rigid body translation across antiphase boundaries in GaAs."

C156 J. G. Maggard, N. D. Theodore and C. B. Carter, 1990, Proc XIIth Int. Cong. for EM, Seattle 4, Pp378-379, "The Behavior of an $\alpha$-Alumina Twist Grain-Boundary in the Presence of Silica."

C168. McKernan, S., Carter, C.B. and Elgat, Z., 1991, Mat. Res. Soc. Symp. Proc., submitted. "Defects in The Structure of $\Sigma 27<110>$ Tilt Grain-Boundaries in Ge."

C174. McKernan, S., Rasmussen, D. R. and Carter, C. B., 1991, Microscopy of Semiconductors, Inst. Phys. Conf. Ser. 117, 139-142, "The Measurem if the Rigid-Body Translation Across the $\{111\}$ APB Facet in GaAs."

C176. McKernan, S., Elgat, Z. and Carter, C. B., 1991, Microscopy of Semiconductors, Inst. Phys. Conf. Ser. 117, 113-116, "The structure of twist units in a Ge $\Sigma=27<110>$ tilt grain-boundary."

G012. Susnitzky, D.W., 1988, Cornell Engireer, "Transmission Electron Microscopy of Ceramics."

Invited Talks Concerning this Program, 1988-

21. "High-Resolution Microscopy of Ceramics"1 Dec., 1988, MRS Symposium on "HighResolution Electron Microscopy," (Chairs: W. Krakow, F. Ponce and D.J. Smith) Boston, 1 Dec., 1988. 
22. "Grain Boundaries and Phase Boundaries in Ceramic Oxides," January, 1988, Argonne National Labs, Argonne, Il.

23. "Structure and Microstructure of Grain Boundaries and Interfaces of Ceramic Materials," (2 Invited Tutorial Lectures)Sept. 1988, NATO Advanced Study Institute Workshop on Surfaces and Interfaces of Ceramic Materials, Oléron, France.

24. "Interfaces in Ceramic Oxides," 20 Sept., 1988, ONERA, Paris, France.

25. "Surfaces and Internal Interfaces in Ceramic Oxides," 5-7 April, 1988, EM West: the 14th Western Regional Meeting of Electron Microscopists and Microanalysists, Long Beach, CA.

27. "Interfaces in High-Tc Superconductors," August, 1989, Annual Meeting of EMSA, San Antonio, Texas.

29. "Simulation and Processing of Images in Electron Microscopy," September, 1989, 12th International Congress on X-ray Optics and Microanalysis (12 IXCOM), Krakow, Poland.

32. "Recent Applications of TEM to the Study of Interfacs: $s$," 12 th International Congress on Electron Microscopy, Seattle, Washington, August 11990.

35. "New Approaches for Studying Interfaces in Oxides," University of Minnesota, 4 Dec. 1990.

37. "Interfaces in Ceramics," N. Ohio Section of the Am. Ceram. Soc., Cleveland, 31 May 1991.

38. "Interfaces in Ceramics," MRS, Fall Meeting, Boston, Nov. 1991.

Other Conference Activities Related to this Program, 1988-

2. Session Chairman, MRS Symposium on "Characterization of Materials," Boston, Mass, Dec.

6. Session Chairman, MRS Symposium on Grain Boundaries, Reno, Nevada, April 1988.

7. Session Chairman, Am. Ceram. Soc. Annual Meeting, Cincinnati, Ohio, May 1988, "Thin Films; Processing and Properties."

8. Program Chairman, Electron Microscopy Society of America (All technical asfects of the meeting), Milwaukee, August, 1988.

9. Symposium Organizer, Am. Ceram. Soc. Basic Science Division 1988 Fall Meeting, "Interfaces in Ceramic Materials," San Francisco, CA, October 1988.

12. Symposium Organizer, "Fine Structure of Defects," 12th International Congress on Electron Microscopy, Seattle, Washington, August 1990.

13. Focussed Session Organizer with Dr Paul Bristowe, MIT," Computer Modeling and Experimental Study of Grain Boundaries," Annual Meeting of the American Physical Society, Annaheim, CA. March 1990.

14. Symposium Organizer, "New Applications of HREM," Electron Microscopy Society of America, San Jose, August, 1991.

15. Session Chairman, MRS Symposium on Interfaces, Boston, Mass, December 1991.

16. Symposium Organizer, "Interfaces," Electron Microscopy Society of America, Boston, August, 1992.

Unpublished Contributed Talks from our DoE Programs, Nov. 1988-

Papers presented at the World Materials Congress. Chicago, 1988.

3. D.W. Susnitzky, S.R. Summerfelt, Y.K. Simpson and C.B. Carter "Phase-Boundary Structure in Ceramic Oxides."

Papers presented at the Annual Meeting Am. Ceram. Soc. 1989

4. G. Y. Sung* and C. B. Carter, "Formation Process and Microstructure of the BiRich Intergranular Layer in the ZnO Varistor Systems."

7. D. W. Susnitzky *, S. McKernan and C. B. Carter, "TEM studies of the Structure of Ceramic Surfaces."

8. D. W. Susnitzky*, and C. B. Carter, "Structure of $\alpha-\mathrm{Al}_{2} \mathrm{O}_{3}$ Grain Boundaries Prepared With and Without a Thin Amorphous Intergranular Film."

Papers nresented at the Annual Meeting Am. Ceram. Soc. 1990

6. S. McKernan, M.G. Norton, C.B. Carter, "Microstructure and Reactions of Aluminum Nitride Ceramic Substrates." 


\section{§10 Personnel INVOlved in THIS DoE Programs}

Historical Background: The predecessor of this program began July 15, 1982, and terminated in November 1988. It was supported for the first two years at the level of one student and one postdoctoral associate. Increasing fixed costs subsequently necessitated that support be changed to two graduate student. In the final year (86/87), support was again changed to the level of one student and, for 5 months, one postdoctoral associate. In the final 18 months of the program, this level of support was gradually decreased allowing David Susnitzky to complete his studies.

$\begin{array}{ccc}\text { Year } & \text { Students } & \text { Postdoc } \\ 1982-83 & 1 & 1 \\ 1983-84 & 2 & 0 \\ 1984-85 & 2 & 0 \\ 1985-86 & 2 & 0 \\ 1986-87 & 1 & \text { part-year } \\ 1987-88 & 1 & \text { part-year } \\ 1988 & 1 & 0 \\ 1988-9 & 2 & 25 \% \\ 1989-90 & 2 & 25 \% \\ 1990-1 & 2 & 25 \%\end{array}$

Personnel supported during 1988 - 1991.

C.B. Carter, Principal Investigator.

René Rasmussen (Ph. D. Jun. '90; Copenhagen) was supported, in part, by this program as a visiting scientist.

Dr Stuart McKernan is a Research Associate was supported by this program 25\% time. Mike Mallamaci (Cornell Ph. D. graduate student) was fully supported by this program. Huyang Xie (Cornell Ph. D. graduate student) was fully supported by this program. 

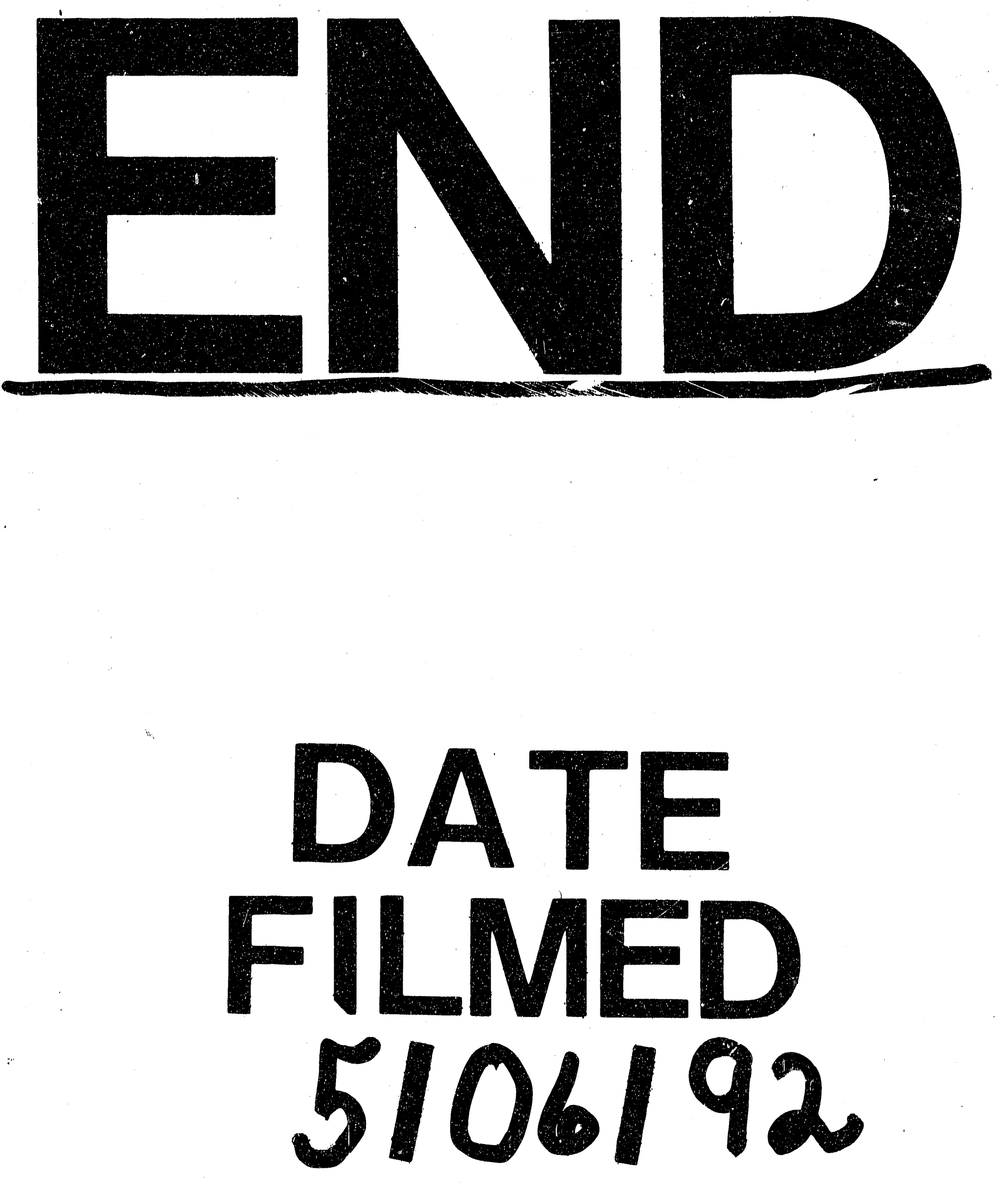